\title{
Rodrigo Rey Rosa (2009), El material humano, Barcelona: Anagrama.
}

\author{
Ester Hernández-Palacios
}

$\mathrm{H}$

e dedicado casi toda mi vida académica más de 30 años de investigadora y docente en la Universidad Veracruzana - al estudio y la enseñanza de la poesía mexicana; sin embargo, en los últimos dos años he incursionado en la lectura y el análisis de otro tipo de obras literarias: novelas y testimonios que se ocupan de representar la violencia en Hispanoamérica. La razón de este cambio no obedece solamente a cuestiones propias de mi desarrollo profesional - pertenencia a un cuerpo académico que ha decidido tratar prioritariamente el tema de la violencia en la literatura hispanoamericana-, sino a que vivo en una región y dentro de una familia cuya vida cotidiana se ha visto violentada profundamente debido a la guerra supuestamente de "baja intensidad" que el gobierno de la República libra contra el crimen organizado.

Así como las fronteras entre la ficción y el testimonio se diluyen en el texto de Rey Rosa, se deshacen también las fronteras entre la vida y la literatura en momentos críticos como los que estamos viviendo. Escribir sobre la violencia se convierte entonces, más que en una mera elección estética o una consecuencia "académica", en un compromiso ético que replantea cuestiones tales como la utilidad y el sentido de la literatura y, por supuesto, de las investigaciones y la crítica literarias. Lo anterior no implica que el rigor teórico y metodológico se diluya, sino que todos los elementos de la investigación deben responder a y ser coherentes con este compromiso.

La literatura hispanoamericana ofrece muchos ejemplos de textos que se ocupan del tema de la violencia, abordada desde diversas perspectivas. Destaca entre ellos el corpus de la literatura guatemalteca, sin lugar a dudas porque es uno de los países de nuestro continente cuya historia ha discurrido con menor tranquilidad. Como afirma Dante Liano, creador, crítico y teórico literario, en la literatura de Guatemala la violencia es el tema por excelencia.

La obra de Rodrigo Rey Rosa no es una excepción dentro de la narrativa de su país de origen, sin embargo, plantea una forma distinta de representarla que, como gran parte de la narrativa contemporánea, pone en entredicho la tradición, los moldes, los géneros, las corrientes y los estilos. Leer su obra representa un reto no menor ya que habrán de ponerse en entredicho

Ester Hernández Palacios, Universidad Veracruzana. 
muchos de los supuestos teóricos, sobre todo aquel que separa la realidad de su representación y la ficción de la verdad.

En el capítulo titulado "La narrativa de la violencia" de su imprescindible volumen Visión crítica de la literatura guatemalteca, afirma Dante Liano:

Cuando se habla de literatura y violencia en Guatemala no se hace ningún esfuerzo peculiar. Quiero decir, mientras en otros contextos literarios se trataría de un subtema muy específico, en el contexto guatemalteco se trata del tema por excelencia. El encuentro con la violencia, aunque sea de manera fortuita, es una probabilidad no desdeñada en la cotidianeidad de un guatemalteco, independientemente de la clase social a la que pertenezca.

El material humano de Rodrigo Rey Rosa, tal vez el escritor guatemalteco más leído dentro y fuera de Latinoamérica después del Premio Nobel Miguel Ángel Asturias, no escapa a lo antes descrito. Publicado en la colección Narrativas Hispánicas de la prestigiosa editorial española Anagrama en 2009, este libro, al que no me atrevo a denominar novela, aborda, a partir de la experiencia escritural de un diario del autornarrador, o sea bajo la forma de testimonio, la vida cotidiana en Guatemala. Y, por supuesto, su tema es la violencia. Si bien en entregas anteriores Rey Rosa había incursionado en otros tópicos, o por lo menos en experiencias violentas en otras latitudes geográficas - como por ejemplo en La orilla africana-, en ésta, de vuelta su autor en su país natal, ${ }^{1}$ regresa también al tema por excelencia de su literatura, si bien lo hará de una manera novedosa. En el mismo trabajo, Dante Liano clasifica a las obras literarias de su país cuando afirma:

Una visión de conjunto de la literatura contemporánea de Guatemala, esto es, elaborada a partir de 1954, nos da cuenta de la existencia de tres tipos de obras: 1. Obras testimoniales, como Los días de la selva de Mario
Payeras o como Me llamo Rigoberta Menchú de Elizabeth Burgos; 2. Obras de denuncia: aquellas que de una u otra manera, siendo principalmente obras literarias también denuncian la situación de violencia en el país; 3. Obras de violencia oblicua: aquellas en las que, por voluntad del autor o, a pesar de la voluntad del autor, la violencia aparece de manera escondida.

El material humano pertenece a la vez al primero y al segundo inciso. Regresemos al texto de Liano: "La característica fundamental de la literatura testimonial es su hibridez, vale decir, son obras que, por sus características de contenido, pertenecen a diversos géneros. Son autobiografía, historia, antropología, política y también Literatura."

Para referirnos a Rey Rosa también debemos modificar el texto de Liano. El material humano no es "también", sino "antes que nada", literatura.

La violencia de este "material" es anterior y contemporánea al momento de la escritura. Abarca no sólo la temporalidad que inicia en 1954, fecha que marca la enorme fractura que se produjo en Guatemala a raíz del golpe de Estado de ese año, sino una anterior, la de los orígenes del conflicto indígena y la de las fechas de nacimiento de los "fichados" que conforman la gran mayoría del "material" y que se remontan más o menos a 1910.

De acuerdo con Dante Liano, el año 1954 también "sanciona el establecimiento en el extranjero, de los intelectuales que hasta el momento habían dominado la cultura del país y que la siguen influyendo desde afuera”. Aunque Rodrigo Rey Rosa será el primero, o uno de los primeros, en regresar a su país después de los años formativos del autoexilio, y pese a editar su obra y alcanzar reconocimiento fuera de Guatemala, escribe y vive en su país.

El autor-narrador escribe este libro situado en la capital de su país natal y lo presenta con la doble cara de realidad y ficción. La escritura se inicia bajo el pretexto de organizar desde su inicio una exhaustiva 
revisión del Gabinete de identificación del Archivo de la policía guatemalteca con la finalidad de conocer los casos de intelectuales y artistas "que fueron objeto de investigación policiaca -o que colaboraron con la policía como informantes o delatores - durante el siglo XX."

Esta investigación se plantea como posible gracias a la existencia de un personaje tan importante como misterioso, el jefe del Proyecto de Recuperación del Archivo. Con este fin que, más temprano que tarde, se convierte en un mero pretexto para introducirse e introducirnos en las múltiples formas que la violencia ha tomado en su país, el narrador - iautor? - de estas 180 páginas da comienzo a un diario que le permitirá registrar todos los pasos de su trabajo y que dará estructura a su relato dividido en libretas y cuadernos - marcados con características tales como "pasta blanca", "pasta española" o "cubierta de cuero sin marca ni nombre" que el autor introduce para reforzar la pertenencia del texto a la escritura de investigación y testimonial一. La investigación histórica inicial lo conduce, podría decir "sin remedio", pero prefiero decir "con sencillez", a su historia personal, particularmente al secuestro de su madre muchos años atrás, aunque también a la historia de su familia, al suicidio del abuelo materno, al origen italiano de su rama paterna, y a su historia familiar cotidiana: la forma de vida de sus hermanas, el exilio voluntario, las amenazantes llamadas telefónicas, su relación amorosa o su faceta de padre, hijo y hermano.

Dicho de otro modo: la investigación del archivo que sirve de punto de partida para la escritura de los cuadernos se transformará en la escritura de un diario; Elmaterial humano inicia como proyecto social y termina como proyecto individual, aunque lo individual resulte la forma "verdadera" - éticamente hablando-dellegar a lo colectivo. Y nunca se pierda de vista la premisa de condensar, en pocas páginas, múltiples historias de vida siempre ligadas a la violenta historia de Guatemala. Así, por ejemplo, en las primeras páginas del libro encontramos, condensadas en apenas unas líneas, las terribles y deprimentes historias de vida contenidas en las fichas del Gabinete de identificación del Archivo que el narrador/autor investiga:

Ávila Aroche Jesús. Nace en 1931. Moreno (1.86 mts). Marimbista. Soltero. Vive con su mamá. Fichado por limpiar botas sin tener licencia. En marzo de 1962 por hurto. En diciembre de 1962 por robo. En mayo de 1963 por secuestro.

Figueroa Estrada Rafael. Nace en 1924 en la capital. Agricultor. Fichado en 1955 por terrorista.

Sarceño O. Juan. Nace en 1925. Jardinero. Vive con su hermana. Fichado en 1945 (Gobierno de la Revolución) por bailar tango en la cervecería "El Gaucho", donde es prohibido.

Fichas Post Mortem

XX. Atado de pies y manos con mecate de plátano, golpeado y lanzado al río. Aclaración: al proceder a la toma de impresiones al cadáver ya mencionado tropecé con la dificultad de que los dedos los tenía churucos, haciendo difícil tomar la huella rodada, aunque procedía a la inyectada, pero tampoco me dio resultado. No me quedó más remedio que cortarle los dedos que mejor consideré para el efecto. Firma José Héctor Terraza T. 7 de diciembre de 1974.

Nota: En un sobrecito adjunto a esta ficha encontré una tira de papel con el diagrama impreso para marcar las huellas digitales. Y allí, en lugar de las típicas manchas de tinta, estaban unos trocitos de tejido que recordaban pétalos de rosa secos, con dibujos dactilares. Examinados más de cerca resultaron ser de piel humana.

El Archivo se convierte así en una alegoría del mundo, poblado de seres infelices o, en todo caso, en una más pequeña de Guatemala. Aunque es probable que, como confesará en la página 6l, el archivo siempre haya sido planteado como una ficción o una puerta de entrada a la ficción: “...mi interés en el Archivo como objeto 
novelable, que comenzaba a declinar, despertó de nuevo a raíz de esta llamada."

Pero volvamos al inicio del libro que, para complicar más las cosas, posee una "introducción" que lo aleja del género novela, es decir, de la ficción, y lo acerca al género testimonio, que traduce o intenta traducir al lenguaje la realidad de manera directa y que coloca a los lectores in mesa res, es decir, en el ojo del huracán o en el centro de la violencia, ya que el narrador, antes de referirse al archivo, cuenta, en el lenguaje frío de quien realizará una investigación "científica", la existencia de un incendio y múltiples explosiones, precisamente en un almacén de proyectiles. Las casi cuatro páginas introductorias continúan contando la historia del Archivo y del Gabinete, un departamento del mismo, de especial interés para el investigador, así como la imposibilidad de consultar las fichas posteriores al año 1970 debido a que los casos a los que hacen referencia "podían estar todavía activados o pendientes en los tribunales."

La escritura neutral y la denominación del texto inicial como "Introducción" no impiden que aparezca un personaje cargado de simbología por su nombre propio, Ariadna Sandoval, cuya única aparición en la obra servirá sólo para introducirnos en la trama con la intuición de que entramos en un laberinto. Un "polvoriento laberinto", como llamará el narrador al Archivo en la página 143, o un laberinto literario y vital: un laberinto de papel para la construcción de refugios, casas de bajo costo para gente miserable o para la simple construcción poética: "Pienso en la construcción con 'bloques-Barceló de un refugio-laberinto que también podría servir de alegoría."

La búsqueda de las fichas que le permitirán conocer la historia de sus antecesores - artistas e intelectuales guatemaltecos- llevará al investigador al encuentro con otro personaje muerto ya en el momento de la investigación, Benedicto Tun, un policía de origen indígena y de extraordinaria inteligencia, fundador del Gabinete de identificación en 1922 y que trabajó en la organización y consulta de las fichas hasta 1970. Benedicto Tun, más que el protagonista de esta trama es el antagonista del personaje principal, el autor/ narrador; y su hijo, del mismo nombre, será uno de sus principales interlocutores a lo largo del libro.

Las interrogaciones se multiplican a medida que la lectura avanza. ¿Cuál es el contrato de lectura que el autor quiere firmar con su lector? Para responder a esta pregunta es necesario detenernos en la primera y la última página del libro que están —no de manera azarosa - fuera de la numeración de las páginas del mismo. Al abrir el volumen, después de la dedicatoria leemos casi a la mitad de la página en blanco: "Aunque no lo parezca, aunque no quiera parecerlo, ésta es una obra de ficción" que parece contradecirse con la escrita en el mismo lugar en la página final, anterior al índice: "Nota: algunos personajes pidieron ser rebautizados."

La historia que se cuenta en las 179 páginas del relato es verdadera, aunque algunas de las historias de los múltiples personajes que las conforman no tengan o hayan tenido un referente de carne y hueso. Personajes que constituyen varios cientos si contamos, además de los amigos, parientes y empleados del archivo, a los muchos escritores que aparecen en el libro por metonimia a través de sus citas y epígrafes; si contamos, decía, los más de cien nombres que corresponden a las fichas del archivo, que condensan sus vidas desdichadas y que dan nombre y sustancia al libro, "material" humano no es un título azaroso ni superfluo. La historia narrada es verdadera en la medida en que lo es la historia de Guatemala en las últimas décadas: los golpes de Estado, la insurgencia, la política de exterminio de los grupos originarios mayenses - por cierto, vale la pena comentar que Benedicto Tun pertenece a una de estas etnias-, los paramilitares, la contrarrevolución, la violencia revolucionaria, la delincuencia común, la pobreza extrema

La ficción puede consistir en la creación de personajes: Benedicto Tun, su hijo del mismo nombre y su nieto Édgar; el "jefe" del proyecto de recuperación 
del Archivo; anécdotas, ambientes, escenas para recrear y dar singularidad literaria a esa historia, esto es, la ficción está en la forma, o parte de la forma, que se da a la historia. El testimonio está en otra parte de la "forma", aquella que corresponde al "diario" que le permite al autor/narrador hablar de su vida privada cotidiana, de sus viajes a Oaxaca y a París para visitar a amigos que existen en el mundo real y asistir a eventos que posiblemente sí sucedieron. Podría haber buscado en Internet la realización de la "Mesa Redonda de Escritores Internacionales" que debió llevarse a cabo en San Agustín Etla en 2005, en la que participó el autor, según narra en su diario, o la exposición de Miquel Barceló en una Galería de París en el mismo año, pero no tendría ningún sentido constatar la verdad o ficción de estos detalles porque no interesan para los términos en que Rey Rosa plantea la relación y el valor de la realidad y la ficción. A fin de cuentas, ambas posibilidades son válidas siempre y cuando partan de y regresen al "material humano."

Si el problema indígena y la terrible política de exterminio que Guatemala llevó a cabo en las primeras décadas del siglo XX, y que Rey Rosa relacionará con los planteamientos de Miguel Ángel Asturias, ${ }^{2}$ a quien se referirá más de una vez siempre con un afán desacralizador, están presentes como telón de fondo en el libro, el mestizaje se transformará, de tema, en herramienta constructiva del discurso. Mestizaje entre ficción y no ficción, entre consciente e inconsciente - es decir, entre el mundo onírico y la realidadentre el autor y el narrador, la escritura propia y la ajena, el bien y el mal, la izquierda y la derecha en el ámbito político y, sobre todo, mestizaje múltiple entre los géneros literarios: diario, ensayo, novela, crónica, poesía... e incluso teoría literaria. Y entre éstos y algunos géneros no literarios: ficha, reporte de investigación, documento.

El mestizaje, la hibridez, la ruptura de fronteras como herramienta constructiva, desembocan en el sueño de todo gran novelista: la construcción de la obra total, aquella que logra parecerse a la vida. Y esta totalidad se consigue gracias precisamente a la ruptura de las fronteras, a la destrucción de los muros. Como en la realidad, en el mundo representado en El material humano todo está conectado con todo. Una reflexión lleva a la cita de un autor, un pensamiento a un sueño, una sensación a una certeza, la literatura a la vida y viceversa:

Leo a De Quincey: Ensayos sobre la retórica, el lenguaje y el estilo y por él llego a Salvator Rosa, el "pintor bandido y autor satírico del siglo XVII (iposible antepasado nuestro?) y consentido de los románticos ingleses que escribió: "Nuestra riqueza ha de ser espiritual, y debemos contentarnos con dar pequeños sorbos, mientras otros se atragantan en la prosperidad."

Si bien este aspecto del mestizaje y la ruptura de fronteras merece un tratamiento más cuidadoso y extenso que espero abordar en otro trabajo, quisiera detenerme cuando menos en uno de los binomios derribados: el del bien y el mal que, en el ejemplo que cito, abarca también a aquél de la vida vs la literatura, o sea la realidad y la ficción: Miguel Ángel Asturias, sin duda el autor más importante de la literatura guatemalteca, es retratado como un intelectual retrógrado, fascistoide, defensor de la innata e insalvable inferioridad de los indígenas y de la necesidad de exterminarlos; mientras que el policía Benedicto Tun, que como ya mencioné pertenece a un grupo maya, director e inventor del Gabinete de identificación que contiene las vidas de cientos de seres humanos fichados, detenidos y muchas veces asesinados por la policía o el ejército, resulta ser un hombre íntegro que se niega a firmar el dictamen apócrifo de la muerte del presidente de la República, jugándose con eso la vida y con la seguridad de, por lo menos, perder su puesto que es, al mismo tiempo, el único sentido de su existencia.

También mayor atención merece el tema de la voz narrativa en primera persona, que adquiere un peso 
enorme al diluir las barreras entre autor y narrador, y se transforma en punta afilada de un compás que se clava - nos clava - en su experiencia vital para trazar el círculo que marca el amplio perímetro de su universo literario, que la extensión de este trabajo no me permite desarrollar. Lo mismo sucede con todo el aparato paratextual: citas, epígrafes, en fin, la enorme y diversa presencia de otras escrituras cuya función no puede ser reducida al aspecto del intertexto.

No quisiera, sin embargo, concluir este breve acercamiento a esta obra maestra de Rey Rosa sin deshacer otros muros, los que separan al crítico del lector y a éste de la obra leída, y los que separan a Guatemala de México, para comentar que casi todos los temas y casi todas las vidas que se abordan en El material humano como propios de o pertenecientes a Guatemala pueden, cada vez más, atribuirse o situarse en México.

Si el abuelo suicida del autor/narrador logró traspasar la frontera que separa a su país del nuestro con el fin de deshacerse de la plaga del chapulín desviándola del Petén al territorio mexicano, la violencia que crece peor que una plaga de la naturaleza vegetal en México ha invadido Guatemala, como si este país necesitara un empujón más fuerte hacia el terror —única forma de nombrar el infierno de Guatemala en el último siglo-.
Hace unos cuantos meses un batallón de Zetas cruzó la frontera para asesinar a decenas de trabajadores agrícolas en una finca del mismo Petén asolado por los chapulines en las páginas de El material humano. Entre los pocos responsables de la masacre que fueron detenidos y purgan condena a perpetuidad está un jovencito jalapeño que fue levantado apenas unos meses antes por este grupo criminal.

\section{Notas}

${ }^{1}$ Otro de los grandes temas de la literatura guatemalteca, vinculado en una relación de causa-efecto con el anterior, es el del exilio. Manuel José Arce, otro estudioso de la literatura de Guatemala, afirma en "Guatemala versus Miguel Ángel Asturias. Breve relato de un conflicto" que "casi toda la literatura guatemalteca válida está marcada por el estigma del exilio."

${ }^{2}$ Como bien dice Dante Liano en "El indio en la literatura guatemalteca", Miguel Ángel Asturias, en uno de sus primeros trabajos, "El problema social del indio", comparte las tesis más retrógradas y aberrantes sobre el problema indígena que defendían las clases dirigentes guatemaltecas y que consistían en plantear como única solución para el problema indígena el exterminio y la inyección de sangre nueva proveniente de los países sajones. 